\title{
Estimating the maritime component of aerosol optical depth and its dependency on surface wind speed using satellite data
}

\author{
Y. Lehahn ${ }^{1,2}$, I. Koren ${ }^{2}$, E. Boss ${ }^{3}$, Y. Ben-Ami ${ }^{2}$, and O. Altaratz ${ }^{2}$ \\ ${ }^{1}$ Department of Geophysics and Planetary Sciences, Tel Aviv University, Tel Aviv, Israel \\ ${ }^{2}$ Department of Environmental Sciences, Weizmann Institue, Rehovot, Israel \\ ${ }^{3}$ School of Marine Sciences, University of Maine, Orono, Maine, USA
}

\begin{abstract}
Six years (2003-2008) of satellite measurements of aerosol parameters from the Moderate Resolution Imaging Spectroradiometer (MODIS) and surface wind speeds from Quick Scatterometer (QuikSCAT), the Advanced Microwave Scanning Radiometer (AMSR-E), and the Special Sensor Microwave Imager (SSM/I), are used to provide a comprehensive perspective on the link between surface wind speed and marine aerosol optical depth over tropical and subtropical oceanic regions. A systematic comparison between the satellite derived fields in these regions allows to: (i) separate the relative contribution of wind-induced marine aerosol to the aerosol optical depth; (ii) extract an empirical linear equation linking coarse marine aerosol optical depth and wind intensity; and (iii) identify a time scale for correlating marine aerosol optical depth and surface wind speed. The contribution of wind induced marine aerosol to aerosol optical depth is found to be dominated by the coarse mode elements. When wind intensity exceeds $4 \mathrm{~m} / \mathrm{s}$, coarse marine aerosol optical depth is linearly correlated with the surface wind speed, with a remarkably consistent slope of $0.009 \pm 0.002 \mathrm{~s} / \mathrm{m}$. A detailed time scale analysis shows that the linear correlation between the fields is well kept within a $12 \mathrm{~h}$ time frame, while sharply decreasing when the time lag between measurements is longer. The background aerosol optical depth, associated with aerosols that are not produced in-situ through wind driven processes, can be used for estimating the contributions of terrestrial and biogenic marine aerosol to over-ocean satellite retrievals of aerosol optical depth.
\end{abstract}

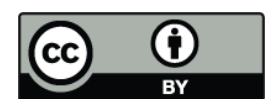

Correspondence to: Y. Lehahn (yoav.lehahn@weizmann.ac.il)

\section{Introduction}

Covering approximately $70 \%$ of the Earth's surface, the World's ocean is one of the major sources of natural aerosol. Marine aerosols play an important role in altering Earth's energy balance, either through direct scattering of solar radiation or indirectly through its effect on cloud microphysical properties, and therefore are important constituents of the climate system and of the hydrological cycle. Changes in marine aerosol properties are likely to have important climatological implications (Murphy et al., 1998; Latham and Smith, 1990; Charlson et al., 1992).

Marine aerosols comprise two components: (i) primary aerosols, which are generated at the sea surface through wind driven processes (especially the bursting of entrained air bubbles associated with whitecap formation) resulting in mechanical production of sea-spray particles and (ii) secondary aerosols, which are the outcome of gas-to-particle processes (O'Dowd and de Leeuw, 2007). In general, marine aerosols contribute to both fine and coarse aerosol modes, with biogenic aerosols (of either primary or secondary origin) mainly contributing to the submicron fine mode and wind induced sea salt particles dominating the supermicron coarse mode. It is well established that the generation of sea spray aerosols (Nilsson et al., 2001), as well as the consequent particle concentration (Hoppel et al., 1990; Glantz et al., 2004; O’Dowd et al., 1997) and size distribution (Hoppel et al., 1990; Gong et al., 1997) are strongly dependent on the wind speed.

Thus, correct representation of marine aerosol characteristics and their dependency on surface wind speed are essential for climate forcing estimations and accurate modeling of the climate system. Currently, our understanding of these phenomena is limited by the availability of observational data.

Published by Copernicus Publications on behalf of the European Geosciences Union. 
Estimates of aerosol parameters such as aerosol optical depth $(\tau)$, fraction of fine $\left(f_{f}\right)$ and coarse $\left(f_{c}\right)$ aerosol and the relative contribution to $\tau$ by fine $\left(\tau_{f}\right)$ and coarse $\left(\tau_{c}\right)$ particles from the measurements of the Moderate Resolution Imaging Spectroradiometer (MODIS) (Remer et al., 2008), in conjunction with satellite estimates of the surface wind speed $(W)$, provide the means for continuous, long term observations of climate forcing.

A major obstacle for making a comprehensive use of satellite data for quantifying phenomena associated with marine aerosols stems from the fact that the majority of the oceans cannot be considered pristine, as they show evidence of aerosol loading from terrestrial origin. Overall, aerosols over the ocean can be classified into three main groups: marine aerosol, anthropogenic aerosol (biomass burning and pollution) and dust. Accordingly, satellite measurements of aerosol optical depth are the sum of contributions from all aerosol groups:

$\tau=\tau_{a}+\tau_{d}+\tau_{m}$

Where the subscripts $a, d$, and $m$ denote anthropogenic, dust, and marine aerosol components, respectively. Currently, our ability to distinguish between the different types of aerosols is limited. Given that the fraction of fine particles in anthropogenic aerosol is much higher as compared to dust or maritime aerosol (Kaufman et al., 2002), a limited classification of aerosol type is possible by the spectral dependence that is linked to the aerosol size. Nevertheless, we do not have an efficient mechanism to distinguish between maritime aerosol and dust in the MODIS data (Kaufman et al., $2005 b$ ). In previous works, $\tau_{m}$ was determined empirically as a constant or as a function of near-surface wind speed from the National Center for Environmental Prediction (NCEP) (Kaufman et al., 2001, 2005a,b).

Here we suggest a novel approach to distinguish the maritime contribution from other components of $\tau$, based on a systematic comparison of satellite measurements of aerosol optical parameters and $W$. We show that satellite-based estimates of surface wind speed can serve as a reliable proxy for the spatial distribution of coarse marine aerosol. More specifically, this work is aimed at providing (i) a mechanism for identifying the maritime component of satellite derived $\tau$ and $\tau_{c}\left(\tau_{c m}\right)$, and (ii) a comprehensive perspective on the dependency of $\tau_{m}$ and $\tau_{c m}$ on $W$.

Previous studies of the link between $\tau$ and $W$ were carried out in specific locations over the world ocean, resulting in a variety of linear (Smirnov et al., 2003; Villevalde et al., 1994), power-law (Mulcahy et al., 2008; Glantz et al., 2009) and exponential (Moorthy and Satheesh, 2000; Vinoj and Satheesh, 2003) relationships between the fields. Exponential increase in aerosol optical depth with increasing wind speeds, were also found by Satheesh et al. (2006) who made use of $\tau$ from MODIS and $W$ from NCEP over the Arabian Sea.
This study is aimed at studying the relationship between marine aerosol optical depth and surface wind speed over different tropical and subtropical regions. The methodology and satellite datasets used in this research are described in the following section. The proposed mechanism for separating the maritime component of $\tau$ and $\tau_{c}$ and the results of the comparison between the fields are described in Sect. 3 followed by a discussion in Sect. 4 and summary and conclusions in Sect. 5 .

\section{Data and methods}

Analysis of the link between aerosol parameters and surface wind speed is based on comparison between satellite satellite-derived fields over a six years period, from 2003 to 2008. In order to cover a wide range of wind and aerosol measurement timings, we use information from 5 polarorbiting satellites, providing 2 aerosol measurements and 6 wind speed measurements per day.

\subsection{Satellite data}

\subsubsection{Aerosol properties}

Aerosol parameters were derived from radiometric measurements of MODIS aboard Terra and Aqua. The two satellites follow a sun-synchronous orbit, providing daily measurements with equatorial crossing times (ECT) at 10:30 (Terra) and 13:30 (Aqua) local solar time (LST). The dataset used here consists of daily global level 3 images of $\tau$ and $f_{f}$ from collection 5 of MODIS aerosol products (Remer et al., 2008), downloaded from the MODIS L1 and Atmospheres Archive and Distribution System (LAADS, http: //ladsweb.nascom.nasa.gov/). The spatial resolution is $1^{0}$. Over-ocean aerosol optical depth and size parameters are standard MODIS products that have been validated extensively against AErosol Robotic NETwork (AERONET) observations on the ground (Remer et al., 2005, 2008).

MODIS over-ocean aerosol retrievals can be disrupted by a number of factors including cloud contamination (Kaufman et al., 2005c; Zhang et al., 2005), and sea surface reflectance by sun glint (Cox and Munk, 1954) and whitecaps (Moore et al., 2000). The latter, which is directly linked to the surface wind speed, may lead to systematic biases (namely underestimates of $\tau$ at low wind cases and overestimates at high winds) in the MODIS over-ocean aerosol retrievals that assume a constant wind speed of $6 \mathrm{~m} / \mathrm{s}$ for estimating reflectance from the sea surface (Zhang and Reid, 2006).

The different factors contaminating MODIS over-ocean retrievals of $\tau$ and $f_{f}$, are especially important in low aerosol loading conditions (e.g. $\tau<0.1$, Kleidman et al.,2005), where MODIS is less sensitive to aerosol characteristics and the accuracy of the retrieval decreases. While the validation of MODIS over-ocean $\tau$ also includes comparison with 
AERONET measurements at low aerosol loading conditions, resulting in a remarkably good agreement, with an estimated uncertainty of $0.03 \pm 0.05 \tau$, validation of $f_{f}$ is still limited to higher $\tau$ conditions (e.g. Kleidman et al., 2005). Recent results from Yu et al. (2009), however show a remarkable consistency between seasonal and geographical variations in $f_{f}$ from MODIS and from two chemical model simulations for pure marine aerosol (defined by the authors as $0.03<\tau<0.10$ ). This indicates that over-ocean MODIS retrievals provide a reliable estimates of $f_{f}$ even in very low aerosol loading condition. This supports Remer et al. (2008) conclusion that over-ocean MODIS $f_{f}$ can be considered as a tested, well-understood product that delivers a quantitative measure of aerosol particle size. In order to avoid biases in aerosol retrievals resulting from cloud contamination effects, all data associated with $\tau>0.7$ were excluded from the current analysis.

\subsubsection{Surface wind speed}

Surface wind speeds (i.e. winds at $10 \mathrm{~m}$ height above sea level) were estimated from measurements taken by three satellite instruments: SeaWinds aboard Quick Scatterometer (QuikSCAT), the Advanced Microwave Scanning Radiometer NASAs Earth Observing System (AMSR-E) aboard Aqua, and Special Sensor Microwave Imager (SSM/I) flown by the Defense Meteorological Satellite Program (DMSP) satellite F15. Data from both ascending (ECT 06:00, 13:30 and 21:00 LST for QuikSCAT, AMSR-E and SSM/I, respectively) and descending (18:00, 01:30 and 09:00) passes were used, resulting in a total of 6 wind speed estimates per day. The wind speed data were obtained from Remote Sensing Systems (RSS), Inc. (http://www.remss.com). The most updated versions of the RSS retrievals (i.e. versions 3, 5, and 6 for QuikSCAT, AMSR-E and SSM/I data, respectively) were used. The data is provided on a $0.25^{\circ}$ global grid.

The three wind sensors used in this research differ in their measuring methods and wind products. While QuikSCAT (Spencer et al., 2000) is an active scatterometer that uses microwave radar for measuring vector winds (i.e. speeds and directions), AMSR-E (Wentz and Meissner, 1999) and SSM/I (Wentz, 1997) are passive microwave radiometers that provide estimates of scalar wind speeds (without directions). Estimates of $W$ from both passive radiometers and active scaterometers were validated against buoy data (e.g., Ebuchi et al., 2002; Mears et al., 2001), and, despite the differences in measuring methods, show good agreement (Wentz et al., 2007). In order to avoid errors resulting from rain effects on scatterometer wind retrieval (Weissman et al., 2002) rain flags were used to identify and mask rainy pixels in the QuikSCAT data (AMSR-E and SSM/I do not retrieve winds in rain).

\subsection{Regions of interest}

The comparison between wind speed and aerosol parameters was performed over $55 \times 5^{\circ}$ regions of interest (ROI) (regions a-e in Fig. 1a). In order to minimize contribution from terrestrial sources, the ROIs were defined in areas that are (i) located away from known sources and transport routes of terrestrial aerosol and (ii) characterized by low mean $\tau$ and hence less affected by long-range aerosol transport. Another issue that was taken into consideration when choosing the ROIs is the importance of time difference between the wind and aerosol measurements (see Sect. 3.2. for a detailed analysis). In order to avoid diurnal changes associated with sea breeze, the ROIs were defined in regions away from the coastline, where sea breeze has litlle or no effect on the wind regime (Gille et al., 2003). Finally, in order to reduce the likelihood of using erroneous aerosol retrievals (Sect. 2.1.1) we avoid data from the "roaring forties" (i.e. Southern Hemisphere mid-latitude oceans), where $\tau$ retrievals are considered to be most vulnerable to cloud contamination and surface wind speed effects (Zhang et al., 2005; Zhang and Reid, 2006).

Based on these criteria, adequate areas were identified in the North and South Pacific (regions a and b, centered respectively at $177.5^{\circ} \mathrm{W} / 27.5^{\circ} \mathrm{N}$ and $147.5^{\circ} \mathrm{W} / 27.5^{\circ} \mathrm{S}$ ), North and South Atlantic (regions c and d, centered respectively at $37.5^{\circ} \mathrm{W} / 37.5^{\circ} \mathrm{N}$ and $17.5^{\circ} \mathrm{W} / 27.5^{\circ} \mathrm{S}$ ) and the Indian Ocean (region e, centered at $77.5^{\circ} \mathrm{E} / 27.5^{\circ} \mathrm{S}$ ).

\subsection{Statistical analysis}

For each ROI, time series of wind speed and aerosol parameters (namely $\tau, \tau_{c}$ and $\tau_{f}$ ) were extracted separately over $251 \times 1^{\circ}$ cells (each cell covered by one pixel of aerosol data and 16 pixels of wind speed data). In order to avoid extreme (and hence poorly represented) values, the lowest and highest $2 \%$ of the wind speed and aerosol parameters data were excluded. The data were sorted according to $W$ and divided into 30 bins of equal number of observations. Regression equations and correlation coefficients were calculated from the full cloud of data points before binning. The statistical analysis was performed on the daily data, without spatial and temporal averaging.

\subsection{Approach}

In order to separate the maritime component of $\tau$, we suggest a novel method that takes into account the additional (satellite derived) information on the surface wind speed. The approach we take is based on the assumption that, as a first approximation, the component of $\tau_{c}$ that correlates with $W$ over the oceans is the marine component to coarse aerosols, $\tau_{c m}$ (Satheesh et al., 2006). This assumption is supported by Kaufman et al. (2005b) analysis of vertical profiles of wind driven aerosol concentration over the Atlantic Ocean, that 
a) Surface Wind Speed $(\mathrm{m} / \mathrm{s})$

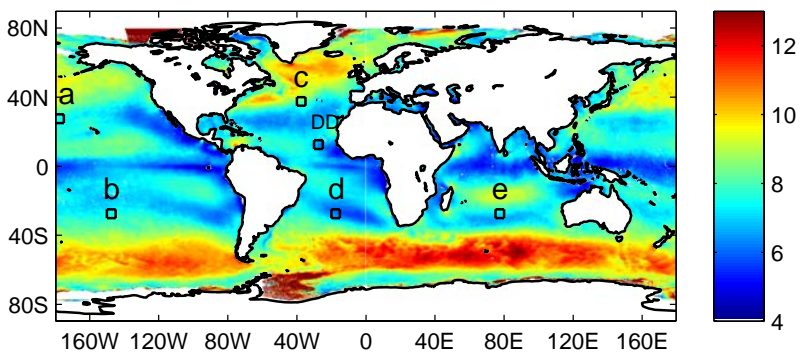

b) Coarse Mode Fraction

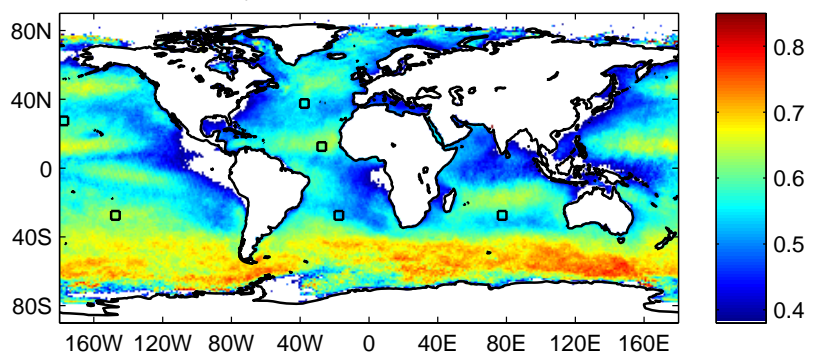

c) Aerosol Optical Depth

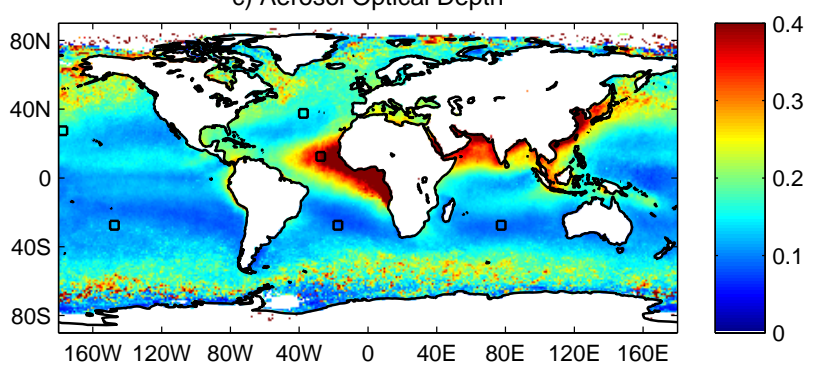

d) Coarse Aerosol Optical Depth

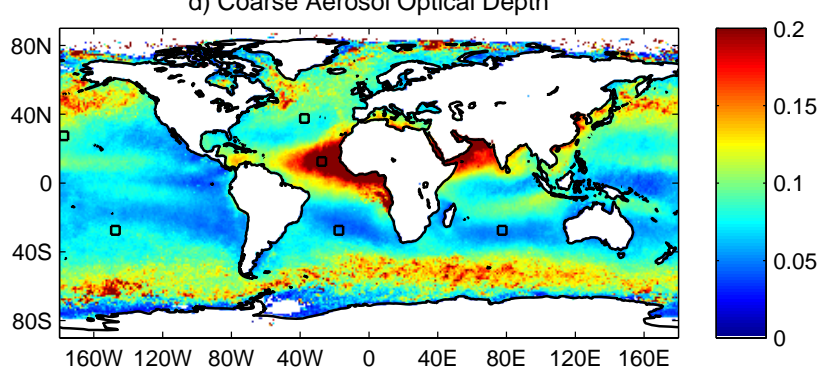

Fig. 1. 2004 annual mean distribution of (a) $W$; (b) $f_{c}$; (c) $\tau$; (d) $\tau_{c}$. The black boxes and the letters in panel a indicate regions used in the analysis presented in the following figures.

showed that the lowest $500 \mathrm{~m}$ of the atmosphere are mostly occupied by sea salt aerosol, whereas dust away from the source is transported at higher altitudes. The lack of correlation between $W$ and the dust component of $\tau_{c}\left(\tau_{c d}\right)$ is emphasized in Fig. 2, where we plot $W$ and $\tau_{c}$ over a $5 \times 5^{\circ}$ region (region DD in Fig. 1a) in an area known to be dominated by desert dust offshore Africa (Kaufman et al., 2002). Regression analysis shows no significant correlation between

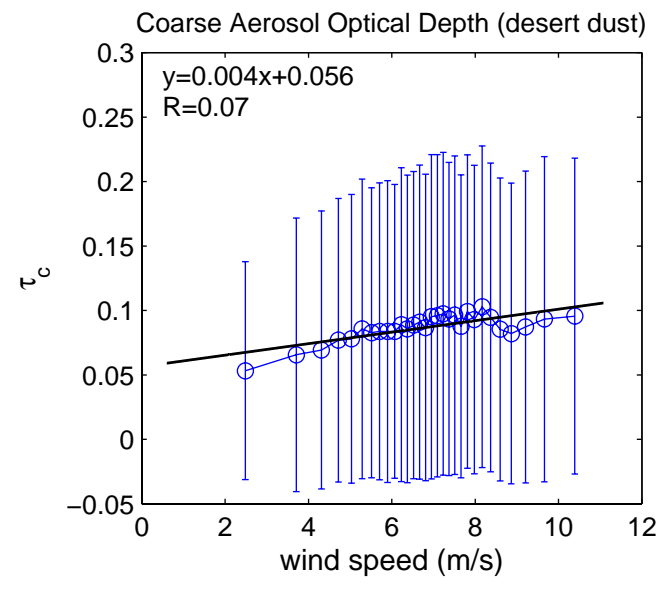

Fig. 2. MODIS-Aqua $\tau_{c}$ plotted against AMSR-E $W$ in an area dominated by desert dust (region DD in Fig. 1a). The data were sorted according to $W$ and divided into 30 bins of equal number of observations. Points and error bars represent respectively the mean and standard deviation of $\tau_{c}$ within each bin.

$W$ and $\tau_{c}$ in this area. Anthropogenic aerosols are predominately fine-mode (Kaufman et al., 2002) and are considered to have very little effect on $\tau_{c}$ (Satheesh et al., 2006).

\section{Analysis and results}

The annual averages of $W$ and $f_{c}$ show similar distribution patterns over large parts of the World Ocean (Fig. 1). Note that the correlation are better over the open oceans away form the shores. Moreover, areas of strong annual winds are characterized by large fraction of coarse mode aerosol and high values of $\tau_{c}$ (Fig. 1d). Regions of moderate winds are usually characterized by a relatively small fraction of coarse mode aerosol and low values of $\tau_{c}$. A different picture is found in the Atlantic Ocean east of Africa and in the Arabian Sea, where prominent features of high $\tau_{c}$ associated with dust (Kaufman et al., 2002) are found in regions of weak or intermediate $W$.

In order to further investigate the relationship between surface wind speed and marine aerosols, In Fig. 3 we plot MODIS-Aqua $\tau_{c}$ against AMSRE-E $W$ at the 5 ROIs. A distinct and repeated characteristics of the $W-\tau_{c}$ relationship, is a significant linear correlation (correlation coefficients, $R$, range from 0.4 to 0.54 and are statistically significant at the $99 \%$ confidence level) between data associated with wind speed higher than approximately $4 \mathrm{~m} / \mathrm{s}$ (red data point in Fig. 3). Furthermore, Over the 5 ROIs, the slope $\left(\alpha_{c}\right)$ linking between the fields is remarkably consistent with an average value $0.009 \pm 0.001 \mathrm{~s} / \mathrm{m}$.

When wind speeds are lower than $4 \mathrm{~m} / \mathrm{s}$, only small changes in $\tau_{c}$ are observed. This results from the low dependency of $\tau_{c}$ on $W$ (e.g. ROI e) and from narrow range of very low winds (less the $2 \%$ of the wind measurements 
Table 1. Regression statistics of aerosol optical parameters versus surface wind speed.

\begin{tabular}{lll}
\hline & $R$ & Reference \\
\hline$\tau_{c m}=0.009 \times(W-4)+0.03$ & 0.5 & current work \\
$\tau_{m}=0.013 \times(W-4)+0.08$ & 0.45 & current work \\
$\tau_{500}=0.0068 \times W+0.056$ & 0.37 & Smirnov et al. (2003) \\
$\tau_{500}=0.00055 \times W^{2.195}+0.06$ & 0.97 & Mulcahy et al. (2008) \\
$\tau_{555}=0.00016 \times W^{2.3}+0.036$ & 0.98 & Glantz et al. (2009) \\
$\tau_{550}=0.004 \times W+0.085$ & 0.96 & Huang et al. (2010) \\
\hline
\end{tabular}

are lower than $2 \mathrm{~m} / \mathrm{s}$ ). The small variability of $\tau_{c}$ at low winds, allows us to identify a background aerosol $\left(\tau_{c 0}\right.$, marked by the horizontal line in Fig. 3) by averaging $\tau_{c}$ associated with winds below $4 \mathrm{~m} / \mathrm{s} . \tau_{c 0}$ is characterized by an averaged value of $0.03 \pm 0.01$. We note that similar results are obtained when using aerosol retrievals from MODIS-Terra in conjunction with wind speeds from SSM/IF15 $\left(\tau_{c 0}=0.04 \pm 0.01, \alpha_{c}=0.008 \pm 0.001\right.$ and $\left.R=0.43 \pm 0.04\right)$ and QuikSCAT $\left(\tau_{c 0}=0.04 \pm 0.01, \quad \alpha_{c}=0.009 \pm 0.001\right.$ and $R=0.44 \pm 0.04$ ) .

Since, as suggested above, any correlation between $W$ and $\tau_{c}$ actually reflects correlation with its maritime wind induced component, $\tau_{c m}$ is calculated as:

$\tau_{c m}=\left\{\begin{aligned} \tau_{c 0}, & \text { if } W \leq 4 \\ \tau_{c 0}+\alpha_{c}(W-4), & \text { if } W>4\end{aligned}\right.$

Further investigation of the link between $W$ and marine aerosol optical properties is done by regressing MODISAqua $\tau, \tau_{c}$ and $\tau_{f}$ against AMSRE-E $W$ for all the data associated with the 5 ROIs (Fig. 4). The relationship between $\tau$ and $W$ for wind speeds higher than $4 \mathrm{~m} / \mathrm{s}$ (Fig. $4 \mathrm{a}$ ) is very similar to the relationship between $\tau_{c}$ and $W$ (Fig. 4b), with a slope $\alpha$ of $0.013 \pm 0.002 \mathrm{~s} / \mathrm{m}$. The background component of $\tau\left(\tau_{0}\right)$ is more than twice higher than $\tau_{c 0}$, with an average value of $0.08 \pm 0.02$.

Hence, equation in the form of Eq. (2), can be used for estimating the wind induced marine aerosol contribution to $\tau$ :

$\tau_{m}=\left\{\begin{aligned} \tau_{0}, & \text { if } W \leq 4 \\ \tau_{0}+\alpha(W-4), & \text { if } W>4\end{aligned}\right.$

The similarity between $\tau$ and $\tau_{c}$ relationships with $W$ can be explained by the low correlation between $W$ and $\tau_{f}$ (Fig. $4 c$ ). Since $\tau$ is the sum of $\tau_{c}$ and $\tau_{f}$, and since $\tau_{f}$ shows little dependency on the wind speed, increase in $\tau$ due to wind driven emission of marine aerosols is attributed almost entirely to contribution from coarse mode particles. $\tau_{f}$ has an important contribution to the part of $\tau$ that is independent of the wind speed (i.e. the background aerosol), with a value of 0.04 accounting for approximately half of the total $\tau_{0}$.
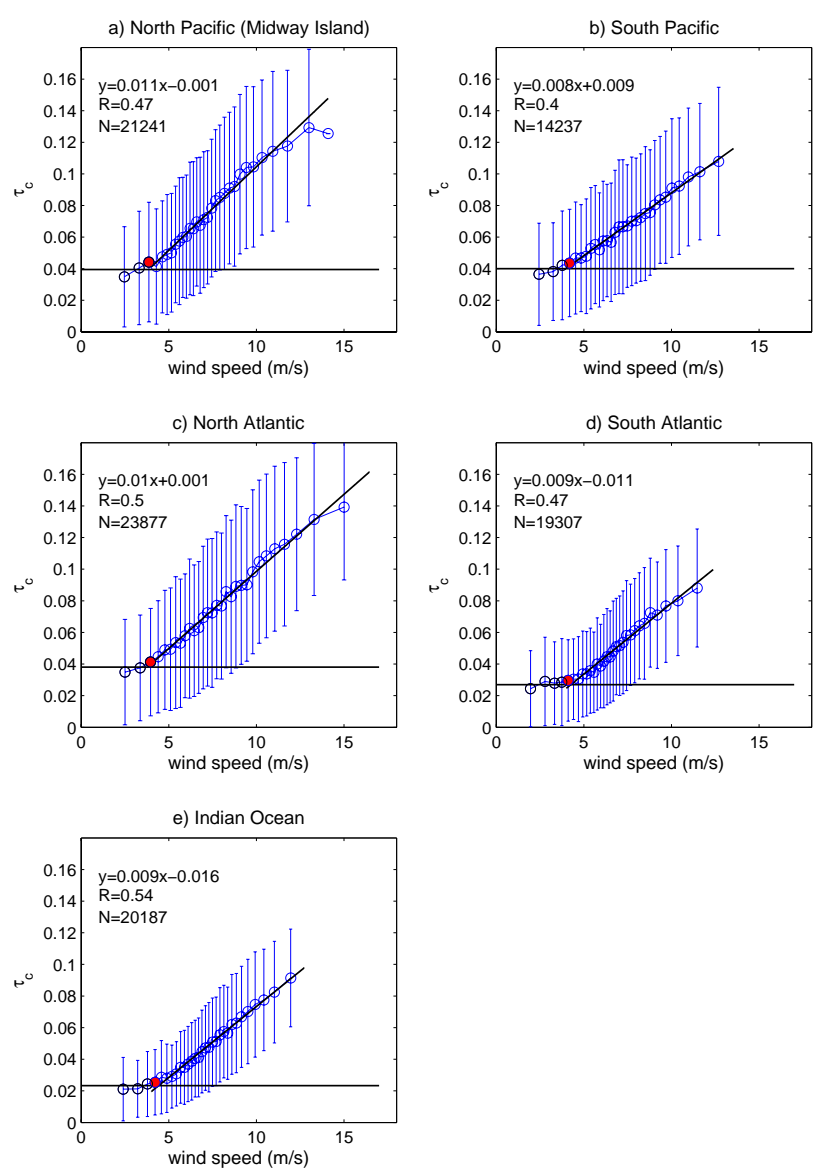

Fig. 3. MODIS-Aqua $\tau_{c}$ plotted against AMSR-E $W$ over the 5 ROIs (regions a-e in Fig. 1). The data were sorted according to $W$ and divided into 30 bins of equal number of observations. Circles and error bars represent respectively the mean and standard deviation of $\tau_{c}$ within each bin. The red data point and the horizontal line mark respectively the threshold wind speed above which $\tau_{c}$ and $W$ are linearly correlated, $W_{4}$, and the value of the background aerosol, $\tau_{c 0}$ (see text). The regression equations and correlation coefficients were calculated from the full cloud of data points before binning. The statistical analysis was performed on the daily data, without spatial and temporal averaging. The regression equations and correlation coefficients were calculated for data corresponding to $W>4 \mathrm{~m} / \mathrm{s}$ and are shown for $\tau_{c}$ after subtracting the background component.

Comparison with previous works that use ground based measurements (Table 1 and dashed lines in Fig. 4a), indicate that over a limited range of wind speeds, the satellitebased linear $\tau_{m}-W$ correlation found here is in good agreement with the ground-based linear relationship obtained by Smirnov et al. (2003) at Midway Island (for $W<7 \mathrm{~m} / \mathrm{s}$ ) and power law relationship obtained by Mulcahy et al. (2008) at the Mace Head atmospheric research station (for $W<12 \mathrm{~m} / \mathrm{s}$ ). We note that recent results from Glantz et al. (2009) estimate the wind induced values of $\tau_{m}$ to be approximately half the ones found here (not shown). 


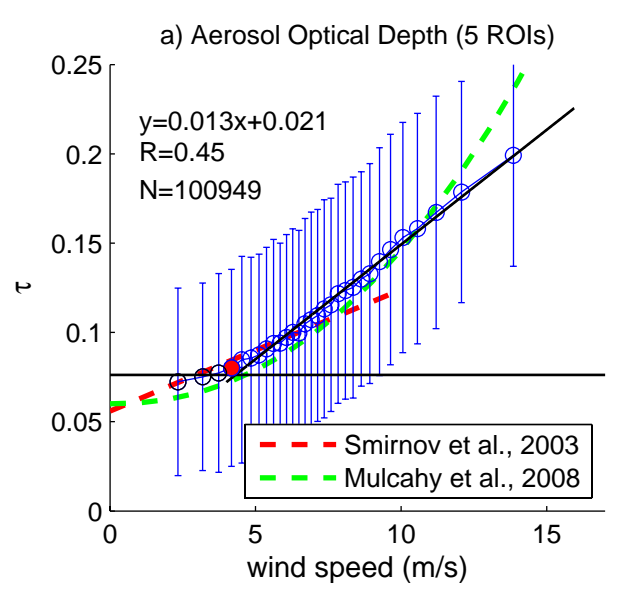

b) Coarse Aerosol Optical Depth (5 ROIs)

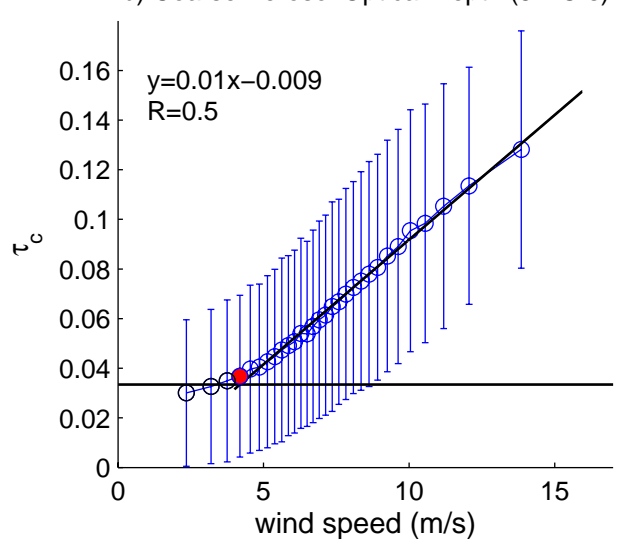

c) Fine Aerosol Optical Depth (5 ROIs)

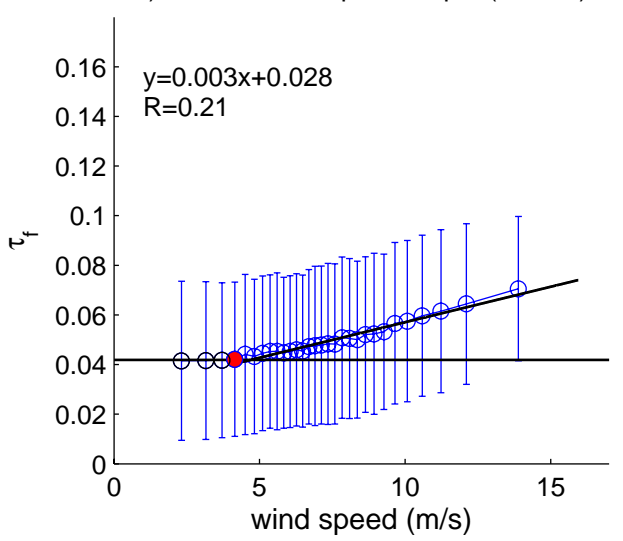

Fig. 4. MODIS-Aqua (a) $\tau$; (b) $\tau_{c}$; (c) $\tau_{f}$ plotted against AMSR-E $W$ over the 5 ROIs (regions a-e in Fig. 1). Binning and statistical operations are similar to those in Fig. 4. The red data points in the upper and middle panels mark $W_{4}$. The horizontal black lines mark $\tau_{0}, \tau_{c 0}$ and $\tau_{f 0}$ (panels a, b, c, respectively). The red and green dashed lines in the upper panel correspond respectively to the relationship between $\tau$ and $W$ found by Smirnov et al. (2003), Mulcahy et al. (2008).

\subsection{Seasonal and geographical variability}

Seasonal and geographical variations in the parameters correlating of $\tau$ and $\tau_{c}$ with $W$ are examined in Fig. 5. The correlation coefficients, $R$ (Fig. 5a and b, respectively) and the slopes $\alpha$ and $\alpha_{c}$ linking $W$ with $\tau$ and $\tau_{c}$ (Fig. 5c and $\mathrm{d}$, respectively), are characterized by a relatively small variability, thus providing an indication to the consistency of the linear correlation between the fields.

Total and coarse background aerosol optical depth (Fig. 5e and $\mathrm{f}$, respectively), are characterized by up to 3 fold variance between different location and seasons. This spatio-temporal variability is mainly attributed to changes in the emission and transport of aerosols from terrestrial sources (Kaufman et al., 2002). Changes in $\tau_{0}$ may also provide indication to seasonal contribution from fine mode biogenic aerosols that show smaller dependency on the surface wind speed.

\subsection{Time scale analysis}

It is acknowledged that generation of sea salt aerosol may depend on the wind speed history (Mulcahy et al., 2008), with a number of studies showing higher correlation coefficients, $R$, when wind speeds are averaged over periods of up to 24 hours prior to the aerosol measurements (e.g., Smirnov et al., 2003; Hoppel et al., 1990). Using data from polar orbiting satellites that, for a given location, are temporally sparse, we focus on estimating the dependency of $R$ on time differences between instantaneous measurements. This is done by performing a lag correlation analysis between $\tau_{c}$ and $W$ over the 5 ROIs, using 12 combinations of aerosol (MODISAqua and MODIS-Terra) and wind speed (ascending and descending passes of AMSR-E, QuikSCAT and SSMI) measurements (Fig. 6). The time difference between the measurements range from 0 to $156 \mathrm{~h}$, with intervals of between 1.5 and $4.5 \mathrm{~h}$. Points and error bars represent respectively the mean and standard deviation of the correlation coefficient for a given time interval at the 5 ROIs. Only data associated with wind speeds higher than $4 \mathrm{~m} / \mathrm{s}$ are used.

Within a time frame of approximately $12 \mathrm{~h}$ the correlation between $W$ and $\tau_{c}$ varies little, maintaining an average value equal or higher than 0.4 (Fig. 6). With increasing time lag, the correlation strongly drops, reaching values lower than 0.1 at a time lag of approximately 3 days. This clear scale break indicates that $12 \mathrm{~h}$ can be considered as the decorrelation time scale between coarse marine aerosol optical depth and surface wind speed. The dependency of $R$ on the time difference between measurements of $W$ and $\tau_{c}$ is partly attributed to the autocorrelation function of tropospheric aerosols, which is characterized by a fairly flat region of high values $(R>0.8)$ for lags below 3-6h, and a rapid decrease at larger scales where time lags are in the order of days (Anderson et al., 2003). 

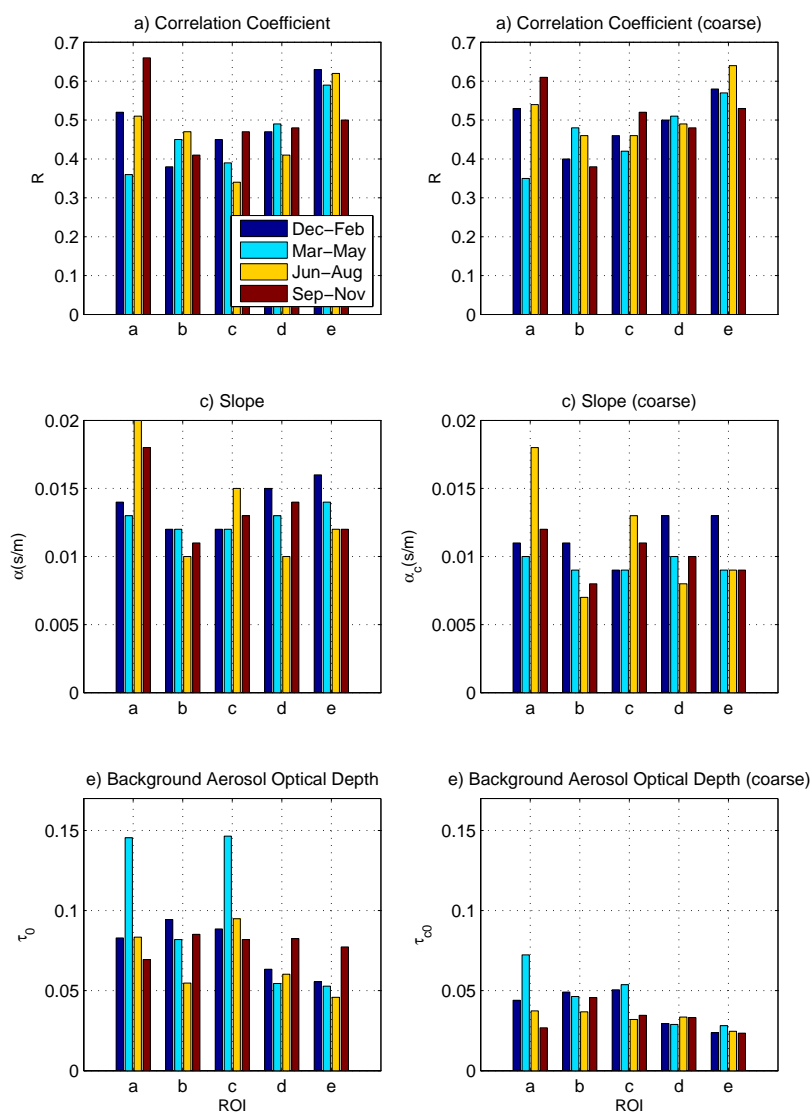

Fig. 5. Seasonal averages of (a) $R ;$ (b) $R_{c} ;$ (c) $\alpha ;$ (d) $\alpha_{c} ;$ (e) $\tau_{0} ;$ (f) $\tau_{c 0}$. The bars are sorted according to the regions of interest (regions a-e in Fig. 1).

\section{Discussion}

The dataset used in this study is well validated against insitu measurements from buoys (for surface wind speeds) and AERONET stations (for aerosol retrievals). Nevertheless, the suggested methodology and consequent results should be considered in view of uncertainties associated with the satellite data.

\subsection{Marine aerosol optical depth or reflectance from whitecaps?}

Since this study is focused on linking marine aerosols and $W$, our main concern is with possible effects of whitecaps that, similarly to marine aerosols, are closely linked to the surface wind speed (e.g., Monahan and O'Muircheartaigh, 1980) and may lead to systematic biases in MODIS over ocean aerosol optical depth retrievals (Zhang and Reid, 2006). The importance of whitecaps to the analysis performed here stems from the fact that at the same time they are directly involved in the process of marine aerosol production, and possibly influence the marine aerosol retrieval by MODIS (by modulating

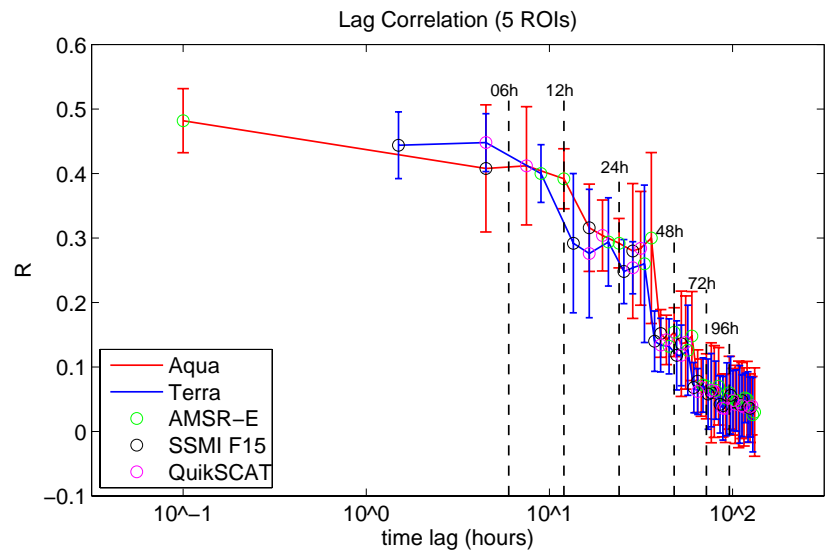

Fig. 6. Correlation coefficients, $R$, between $\tau_{c}$ and $W$ as a function of the time difference between measurements, at the 5 regions of interest (regions a-e in Fig. 1). 12 combinations of aerosol (MODISAqua and MODIS-Terra) and wind speed (ascending and descending passes of AMSR-E, QuikSCAT and SSMI) were used. Time difference between the measurements range from 0 to $156 \mathrm{~h}$, with intervals of between 1.5 and $4.5 \mathrm{~h}$. Points and error bars represent respectively the mean and standard deviation of $R$ for a given time interval at the 5 ROIs. Only data associated with wind speeds higher than $4 \mathrm{~m} / \mathrm{s}$ was used. $12 \mathrm{~h}$ is identified is the decorrelation time scale for linking surface wind speed marine aerosol optical depth.

the reflectance). This is emphasized by the fact that whitecaps reflectance (and the consequent possible errors, $O$, in MODIS aerosol retrievals) is the result of light scattering from bubbles, whose bursting is the major process responsible for sea salt aerosol production.

Consequently, both aerosol production flux and whitecaps reflectance are expected to be proportional to the fraction $\left(f_{w}\right)$ of the sea surface covered by whitecaps, which by itself depends on the surface wind speed (Lewis and Schwartz, 2004). Given that MODIS retrieved $\tau_{c}$ is the sum of the true (i.e. independent of the measuring technique) $\tau_{c m}$ and $O$, and since (i) both $\tau_{c m}$ and $O$ are wind dependent; and (ii) $\tau_{c m}$ is, to a certain extent, $O$ dependent (due to the physical mechanisms leading to marine aerosol production), it suggests that $\tau_{c m}$ can be obtained from MODIS $\tau_{c}$ even in the case that a constant wind induced bias in MODIS aerosol retrieval does exist.

In order to estimate the magnitude of possible retrieval artifacts associated with reflectance from whitecaps, and in order to further reduce the uncertainties associated with the methodology used, we test the dependency on $W$ of $\tau_{c}$ measurements from 7 land-based AERONET stations on remote equatorial and mid-latitudes islands (Fig. 7). The surface effect on the CIMEL sunphotometers (used in AERONET stations) pointing to the sun is assumed to be negligible. Level 2.0 AERONET data were downloaded from the AERONET web-page (http://aeronet.gsfc.nasa.gov/). A daily value was calculated as the mean of all measurements taken between 


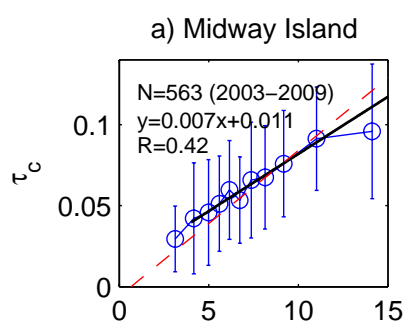

c) Guam

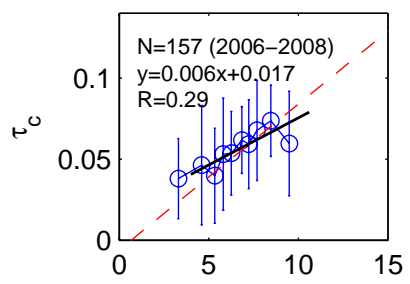

e) Tahiti

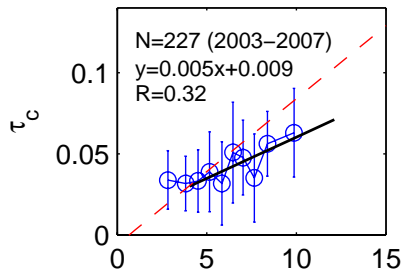

g) Lanai

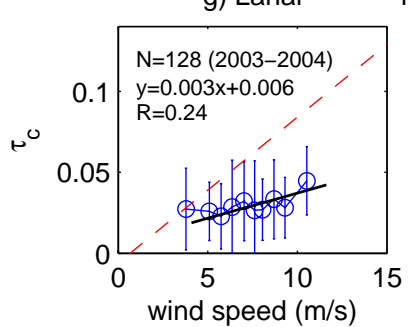

b) Ascension Island

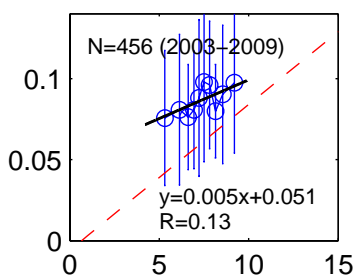

d) Nauru

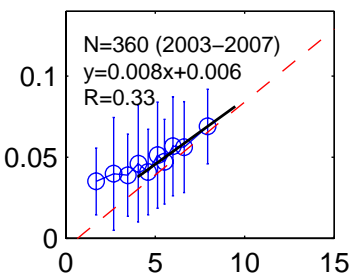

f) Coconut Island

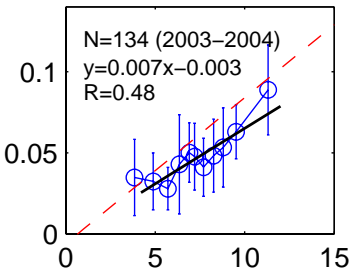

h) Aggregated Dataset(7 stations)

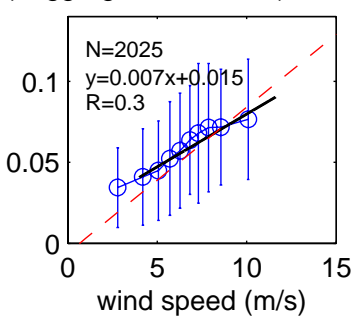

Fig. 7. Coarse aerosol optical depth from seven AERONET stations on remote mid-latitudes and equatorial islands, plotted against AMSR-E $W, \mathbf{a}-\mathbf{g}$ ) separately for each station; and $\mathbf{h}$ ) as an aggregated dataset. The data were sorted according to $W$ and divided into 10 bins of equal number of observations. The regression equations and correlation coefficients were calculated from the full cloud of data points before binning. Circles and error bars represent respectively the mean and standard deviation of aerosol data within each bin. The dashed red line marks the empirical linear relationship between MODIS $\tau_{c}$ and AMSR-E $W$, corresponding to $\tau_{c 0}$ of 0.03 and a slope of $0.009 \mathrm{~s} / \mathrm{m}$ (see text).

13:00 and 15:00. AMSR-E (ascending passes) wind speeds data were averaged daily over a $2 \times 2^{\circ}$ area around the station. Only data associated with wind speeds higher than $4 \mathrm{~m} / \mathrm{s}$ were used for the statistical analysis. At all seven locations, AERONET $\tau_{c}$ is linearly correlated to $W$, with a slope ranging from $0.003 \mathrm{~s} / \mathrm{m}$ (Lanai station, Fig. $7 \mathrm{~g}$ ) to $0.008 \mathrm{~s} / \mathrm{m}$ (Nauru station, Fig. 7d). When correlating an aggregated dataset comprised of data from all 7 stations, the slope linking $\tau_{c}$ and $W$ is $0.007 \mathrm{~s} / \mathrm{m}$ (Fig. 7h). Considering the various factors that may mask the correlation, such as mountainous terrain, limited range of wind speeds and influence of continental aerosols (Smirnov et al., 2003), the link between $W$ and $\tau_{c}$ from AERONET is remarkably similar to the $W-\tau_{c}$ relationship extracted in this work (marked by a red dashed line in Fig. 7)

If we assume that the value of the slope, $\alpha_{\mathrm{c}-\text { aeronet }}$, between $W$ and $\tau_{c}$ calculated for the aggregated ground-based AERONET dataset represent the true dependence of $\tau_{c}$ on $W$, we can now estimate the possible contribution of $O$. Since $\alpha_{c}=0.009 \mathrm{~s} / \mathrm{m}$ and $\alpha_{\text {c-aeronet }}=0.007 \mathrm{~s} / \mathrm{m}$, a value of $0.002 \mathrm{~s} / \mathrm{m}$ can be attributed, as a first approximation, to overestimation of $\tau_{c}$ due to whitecaps, and is used as a measure to the uncertainty associated with possible unaccounted wind induced artifacts (which we consider as the major source of possible error in the current analysis). Similarly, a value of $0.005 \mathrm{~s} / \mathrm{m}$, corresponding to the difference between $\alpha_{\text {aeronet }}=0.008 \mathrm{~s} / \mathrm{m}$ (not shown) and $\alpha=0.013 \mathrm{~s} / \mathrm{m}$, is used as an estimate to possible errors in linking $W$ and total $\tau$.

In addition to the remarkable similarity with $W-\tau_{c}$ relationship from the AERONET stations, the reliability of the satellite derived relationship found here is also strongly supported by the good agreement with the studies of Smirnov et al. (2003) and Mulcahy et al. (2008), which are based on ground measurements and are thus not affected by reflectance from the sea surface (Fig. 4a). Further reduction of the uncertainty associated with aerosol retrieval accuracy is achieved by avoiding the "roaring forties" region, where the effect of cloud contamination and retrieval biases due to wind effects are considered to be especially important (Zhang et al., 2005; Zhang and Reid, 2006). In addition, we note that with $\tau_{0}$, which is independent of the wind speed, having an averaged value of approximately 0.08 (Fig. 4a), most of the wind related variability is associated with $\tau>0.1$, thus not included in the somewhat problematic category of very low aerosol loading conditions. Finally, the reliability of the results, which show a remarkable consistency through various tropical and subtropical locations, is supported by the use a very large dataset that covers a large variety of oceanic and atmospheric regimes throughout a relatively long (6 years) time span, hence including a wide range of wind speeds and aerosol properties.

\section{Summary and conclusions}

Using a systematic comparison between satellite retrieved surface wind speed, aerosol optical depth and aerosol fine mode fraction, we identify the maritime component of over ocean aerosol optical depth, and quantify its dependency on the surface wind speed.

After taking into considerations a number of limitations, the following conclusions are drawn from this study: 
1. Changes in MODIS aerosol optical depth due to wind induced maritime aerosols are dominated by contribution from coarse mode particles. This may suggest a tool for separating relative contributions of sea salt and biogenic marine aerosols.

2. For surface winds higher than $4 \mathrm{~m} / \mathrm{s}$, MODIS coarse marine aerosol optical depth is linearly correlated with the surface wind speed, with a remarkably consistent slope of $0.009 \pm 0.002 \mathrm{~s} / \mathrm{m}$.

3. Over the open sea, in tropical and subtropical regions, the correlation between coarse marine aerosol optical depth and surface wind speed is well kept within a time frame of $12 \mathrm{~h}$, while strongly decreasing for longer time differences between measurements.

4. Assuming that over the open sea, away from the continents, optical depth by other types of coarse particles (such as dust) is not well correlated with surface wind, having the wind information, the total aerosol optical depth and the fine fraction enables estimation of the marine aerosol contribution to the total coarse optical depth and therefore, to a good approximation, the contribution of coarse mode dust. Moreover, by deducting the wind induced marine aerosol, the average background aerosol loading can be estimated per location and season.

Our results significantly improve our ability to distinguish between different aerosol types over tropical and subtropical oceanic regions. This provides a framework for continuous, long term observations on the production of marine aerosols, and on the way they affect, and are affected by, climate variability.

Acknowledgements. We would like to acknowledge the partial support of the Minerva Foundation (grant 780048) and of Yeda-Sela center. We thank Lorraine Remer for very fruitful discussions. The work of Y. L. was supported by the Dan David Prize Scholarship (2008).

Edited by: J. Quaas

\section{References}

Anderson, T., Charlson, R., Winker, D., Ogren, J., and Holmen, K.: Mesoscale variations of tropospheric aerosols, J. Atmos. Sci., 60, 119-136, 2003.

Charlson, R., Schwartz, S., Hales, J., Cess, R., Coakley, J., Hansen, J., and Hofmann, D.: Climate forcing by anthropogenic aerosols, Science, 255, 423-430, 1992.

Cox, C. and Munk, W.: Measurements of the roughness of the sea surface from photographs of the sun's glitter, J. Opt. Soc. Am., 44, 838-850, 1954.

Ebuchi, N., Graber, H., and Caruso, M.: Evaluation of wind vectors observed by QuikSCAT/SeaWinds using ocean buoy data, J. Atmos. Ocean. Tech., 19, 2049-2062, 2002.
Gille, S., Smith, S., and Lee, S.: Measuring the sea breeze from QuikSCAT Scatterometry, Geophys. Res. Lett., 30, 1114, doi:10.1029/2002GL016230, 2003.

Glantz, P., Svensson, G., Noone, K., and Osborne, S.: Seasalt aerosols over the north-east Atlantic: model-2 Second Lagrangian experiment, Q. J. Roy. Meteorol. Soc., 130, 2191-2215, 2004.

Glantz, P., Nilsson, E., and von Hoyningen-Huene, W.: Estimating a relationship between aerosol optical thickness and surface wind speed over the ocean, Atmos. Res., 92, 58-68, 2009.

Gong, S., Barrie, L., and Blanchet, J.-P.: Modeling sea-salt aerosols in the atmosphere 1. Model development, J. Geophys. Res., 102, 3805-3818, 1997.

Hoppel, W., Fitzgerald, J., Frick, G., Larson, R., and Mack, E.: Aerosol size distributions and optical properties found in the marine boundary layer over the Atlantic Ocean, J. Geophys. Res., 95, 3659-3686, 1990.

Huang, H., Thomas, G. E., and Grainger, R. G.: Relationship between wind speed and aerosol optical depth over remote ocean, Atmos. Chem. Phys., 10, 5943-5950, doi:10.5194/acp-10-59432010, 2010.

Kaufman, Y., Smirnov, A., Holben, B., and Dubovik, O.: Baseline maritime aerosol: methodology to derive the optical thickness and scattering properties, Geophys. Res. Lett., 17, 3251-3254, doi:10.1029/2001GL013312, 2001.

Kaufman, Y., Tanré, D., and Boucher, O.: A satellite view of aerosols in the climate system, Nature, 419, 215-223, 2002.

Kaufman, Y., Boucher, O., Tanré, D., Chin, M., Remer, L., and Takemura, T.: Aerosol anthropogenic component estimated from satellite data, Geophys. Res. Lett., 32, L17804, doi:10.1029/2005GL023125, 2005a.

Kaufman, Y., Koren, I., Remer, L.A. Tanré, D., Ginoux, P., and Fan, S.: Dust transport and deposition observed from the Terra-Moderate Resolution Imaging Spectroradiometer (MODIS) spacecraft over the Atlantic Ocean, J. Geophys. Res., 110, D10S12, doi:10.1029/2003JD004436, 2005b.

Kaufman, Y., Remer, L., Tanré, D., Li, R.-R., Kleidman, R., Mattoo, S., Levy, R., Eck, T., Holben, B., Ichoku, C., Martins, J., and Koren, I.: A critical examination of the residual cloud contamination and diurnal sampling effects on MODIS estimates of aerosol over ocean, IEEE T. Geosci. Remote, 43, 2886-2897, 2005c.

Kleidman, R., O’Neill, N., Remer, L., Kaufman, Y., Eck, T., Tanre, D. Dubovik, O., and Holben, B.: Comparison of Moderate Resolution Imaging Spectroradiometer (MODIS) and Aerosol Robotic Network (AERONET) remote-sensing retrievals of aerosol fine mode fraction over ocean, J. Geophys. Res., 110, D22205, doi:10.1029/2005JD005760, 2005.

Latham, J. and Smith, M.: Effect on global warming of winddependent aerosol generation at the ocean surface, Nature, 347, 372-373, 1990.

Lewis, E. and Schwartz, S.: Sea salt aerosols production: mechanisms, methods, measurements and models: a critical review, American Geophysical Union, Washington, DC, 2004.

Mears, C., Smith, D., and Wentz, F.: Comparison of SSM/I and buoy-measured wind speeds from 1987-1997, J. Geophys. Res., 106, 11719-11729, 2001.

Monahan, E. and O'Muircheartaigh, I.: Optimal power-law description of oceanic whitecap coverage dependence on wind speed, J. 
Phys. Oceanogr., 10, 2094-2099, 1980.

Moore, K., Voss, K., and Gordon, H.: Spectral reflectance of whitecaps: Their contribution to water-leaving radiance, J. Geophys. Res., 105, 6493-6499, 2000.

Moorthy, K. and Satheesh, S.: Characteristics of aerosols over a remote island, Minicoy in the Arabian Sea: Optical properties and retrieved size characteristics, Q. J. Roy. Meteorol. Soc., 126, 81-109, 2000.

Mulcahy, J., O’Dowd, C., Jennings, S., and Ceburnis, D.: Significant enhancement of aerosol optical depth in marine air under high wind conditions, Geophys. Res. Lett., 35, L16810, doi:10.1029/2008GL034303, 2008.

Murphy, D., Anderson, J., Quinn, P., McInnes, L., Brechtel, F., Kreidenweis, S., Middlebrook, A., Pósfai, M., Thomson, D., and Buseck, P.: Influence of sea-salt on aerosol radiative properties in the Southern Ocean marine boundary layer, Nature, 392, 62-65, 1998.

Nilsson, E., Rannik, U., Swietliccki, E., Leck, C., Aalto, P., Zhou, J., and Norman, M.: Turbulent aerosol fluxes over the Arctic Ocean: 2. Winddriven sources from the sea, J. Geophys. Res., 106, 32111-32124, 2001.

O'Dowd, C. and de Leeuw, G.: Marine aerosol production: a review of the current knowledge, Philos. T. Roy. Soc. A, 365, 17531774, doi:10.1098/rsta.2007.2043, 2007.

O'Dowd, C., Smith, M., Consterdine, I., and Lowe, J.: Marine aerosol, sea-salt, and the marine sulphur cycle: a short review, Atmos. Environ., 31, 73-80, 1997.

Remer, L., Kaufman, Y., Tanré, D., Mattoo, S., Chu, D., Martins, J., Li, R.-R., Ichoku, C., Levy, R., Kleidman, R., Eck, T., Vermote, E., and Holben, B.: The MODIS Aerosol Algorithm, Products, and Validation, J. Atmos. Sci., 62, 947-971, 2005.

Remer, L., Kleidman, R., Levy, R., Kaufman, Y., Tanré, D., Mattoo, S., Martins, J., Ichoku, C., Koren, I., Yu, H., and Holben, B.: Global aerosol climatology from the MODIS satellite sensors, J. Geophys. Res., 113, D14S07 doi:10.1029/2007JD009661, 2008.

Satheesh, S., Srinivasan, J., and Krishna Moorthy, K.: Contribution of sea-salt to aerosol optical depth over the Arabian Sea derived from MODIS observations, Geophys. Res. Lett., 33, L03809, doi:10.1029/2005GL024856, 2006.
Smirnov, A., Holben, B., Eck, T., Dubovik, O., and Slutsker, I.: Effect of wind speed on columnar aerosol optical properties at Midway Island, J. Geophys. Res., 108, 4802, doi:10.1029/2003JD003879, 2003.

Spencer, M., Wu, C., and Long, D.: Improved resolution backscatter measurements with the SeaWinds pencil-beam scatterometer, IEEE Trans. Geosci. Remote Sens., 38, 89-104, 2000.

Villevalde, Y., Smirnov, A., O’Neill, N., Smyshlyaev, S., and Yakovlev, V.: Measurement of aerosol optical depth in the Pacific Ocean and the North Atlantic, J. Geophys. Res., 99, 983988, 1994.

Vinoj, V. and Satheesh, S.: Measurements of aerosol optical depth over Arabian Sea during summer monsoon season, Geophys. Res. Lett., 30, 1263, doi:10.1029/2002GL016664, 2003.

Weissman, D., Bourassa, A., and Tongue, J.: ffects of rain-rate and wind magnitude on SeaWinds scatterometer wind speed errors, J. Atmos. Ocean. Tech., 19, 738-746, 2002.

Wentz, F.: A well-calibrated ocean algorithm for SSM/I, J. Geophys. Res., 102, 8703-8718, 1997.

Wentz, F. and Meissner, T.: AMSR Ocean Algorithm, version 2, Tech. rep., Remote Sens. Syst., Santa Rosa, California, 1999.

Wentz, F., Ricciardulli, L., Hilburn, K., and Mears, C.: How Much More Rain Will Global Warming Bring?, Science, 317, 233-235, 2007.

Yu, H., Chin, M., Remer, L., Kleidman, R., Bellouin, N., Bian, H., and Dieh, T.: Variability of marine aerosol fine-mode fraction and estimates of anthropogenic aerosol component over cloud-free oceans from the Moderate Resolution Imaging Spectroradiometer (MODIS), J. Geophys. Res., 114, D10206, doi:10.1029/2008JD010648, 2009.

Zhang, J. and Reid, J.: MODIS aerosol product analysis for data assimilation: Assessment of over ocean level 2 aerosol optical thickness retrievals, J. Geophys. Res., 111, D22207, doi:10.1029/2005JD006898, 2006.

Zhang, J., Reid, J., and Holben, B.: An analysis of potential cloud artifacts in MODIS over ocean aerosol optical thickness products, Geophys. Res. Lett., 32, L15803, doi:10.1029/2005GL023254, 2005. 